\title{
Photoimmunotherapy Using Cationic and Anionic Photosensitizer-Antibody Conjugates against HIV Env-Expressing Cells
}

\author{
Mohammad Sadraeian ${ }^{1,+} \mathbb{D}^{-}$, Calise Bahou ${ }^{2}$, Edgar Ferreira da Cruz ${ }^{3}$, Luíz Mário Ramos Janini ${ }^{3}$, \\ Ricardo Sobhie Diaz ${ }^{3}$, Ross W. Boyle ${ }^{4}\left(\mathbb{D}\right.$, Vijay Chudasama ${ }^{2, *}$ \\ and Francisco Eduardo Gontijo Guimarães 1,*

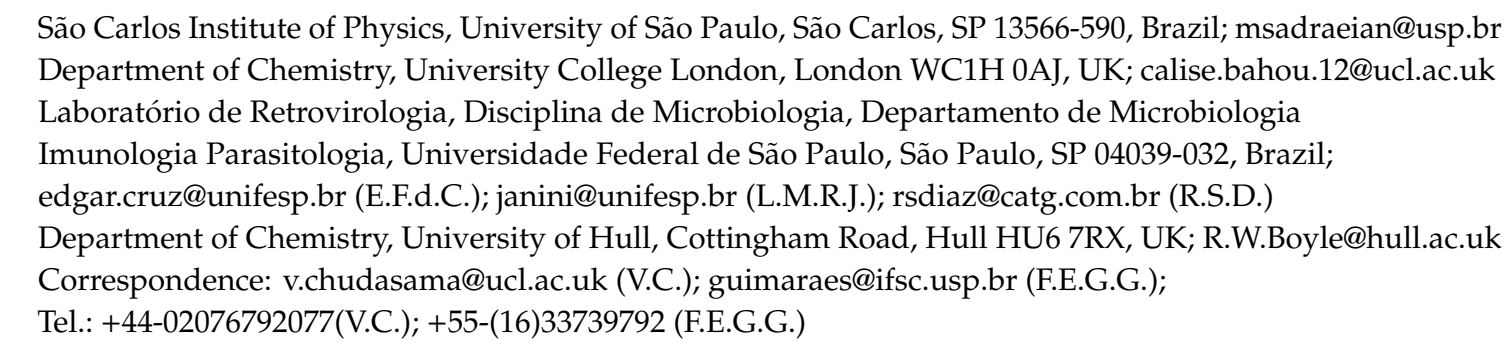

Received: 22 October 2020; Accepted: 21 November 2020; Published: 1 December 2020

\begin{abstract}
Different therapeutic strategies have been investigated to target and eliminate HIV-1-infected cells by using armed antibodies specific to viral proteins, with varying degrees of success. Herein, we propose a new strategy by combining photodynamic therapy (PDT) with HIV Env-targeted immunotherapy, and refer to it as HIV photoimmunotherapy (PIT). A human anti-gp41 antibody (7B2) was conjugated to two photosensitizers (PSs) with different charges through different linking strategies; "Click" conjugation by using an azide-bearing porphyrin attached via a disulfide bridge linker with a drug-to-antibody ratio (DAR) of exactly 4 , and "Lysine" conjugation by using phthalocyanine IRDye 700DX dye with average DARs of 2.1,3.0 and 4.4. These photo-immunoconjugates (PICs) were compared via biochemical and immunological characterizations regarding the dosimetry, solubility, and cell targeting. Photo-induced cytotoxicity of the PICs were compared using assays for apoptosis, reactive oxygen species (ROS), photo-cytotoxicity, and confocal microscopy. Targeted phototoxicity seems to be primarily dependent on the binding of PS-antibody to the HIV antigen on the cell membrane, whilst being independent of the PS type. This is the first report of the application of PIT for HIV immunotherapy by killing HIV Env-expressing cells.
\end{abstract}

Keywords: HIV immunotherapy; photoimmunotherapy; photodynamic therapy; porphyrin; phthalocyanine; HIV-infected cell; monoclonal antibody

\section{Introduction}

Antibody-based therapies have become important clinical tools in treating chronic diseases. Different immunotherapeutic strategies, with limited success, have been investigated to target and eliminate viral-infected cells by using armed antibodies specific to viral proteins [1]. This can be achieved by linking a drug to monoclonal antibodies (MAbs), to form immunotoxins (IT) [2], radio-labeled antibodies [3,4] or other cell-binding conjugates [5,6] capable of specifically killing infected cells, such as HIV infected cells [1,7]. Photoimmunotherapy (PIT) is a targeted photodynamic therapy (PDT) that uses photosensitizer-loaded MAbs. PIT has certain advantages over immunotoxins or 
RIT to eradicate infected cells [8]. In immunotherapy based on immunotoxins, a MAb is conjugated to an immunogenic toxin such as ricin [9], pulchellin [10,11] or shiga toxin [12], which can elicit an immunogenicity exemplified by the anti-toxin response [3,13]. PIT is a minimally invasive treatment, which is safer and cheaper than immunotoxins or RIT [14]. While HIV RIT is drawing the attention of researchers [4], there are no studies on the possibility of HIV treatment by PIT.

In this paper, we propose HIV immunotherapy via arming HIV monoclonal antibodies with photosensitizers (PSs). Anti-HIV immunoconjugates must be targeted to the HIV envelope spike (Env) that consists of gp160 [9,15], gp120 [16], and gp41 glycoproteins [11,16]. Visible-light activated PSs initially form the excited singlet state, which can decay by emitting fluorescence or, alternatively, it reaches the more stable excited triplet state. [17]. This triplet state can involve electron or hydrogen transfer via Type I photochemical mechanisms to yield superoxide, hydrogen peroxide, and hydroxyl radicals (electron transfer process), typical of phenothiazinium dyes [18], or Type II mechanisms (energy transfer process), typical of porphyrins [19,20], and Rose Bengal [21,22]. Reactive oxygen species (ROS) can damage cell membrane via oxidization of lipids, proteins, and nucleic acids, leading to cell necrosis where cells swell and lyse to release their intracellular content causing inflammation, or alternatively cells can undergo apoptosis [23,24]. The conventional treatment using only PS and light is called photodynamic therapy (PDT), which can destroy cells nonspecifically when exposed to light [23]. Related to this, PIT is the targeted form of conventional PDT, achieved through the conjugation of PS with MAbs targeting specific cell surface receptors [14,25]. PIT can also reduce other issues, such as dark toxicity and PS aggregation in aqueous media which reduce PDT efficacy [14]. The conjugation of a photosensitizer to antibodies can be achieved through chemical modification of the $\varepsilon$-amino group present on lysine residues [26] or through reactions with the thiol moiety present on cysteine residues (generated via reduction of interchain disulfide bonds). However, neither of these conjugation strategies is ideal $[27,28]$. Lysine modification can yield heterogeneous products with a broad distribution of drug loading, and conventional cysteine modification methods utilize interchain disulfide reduction, and result in the permanent loss of structural disulfide bonds, which has been shown to potentially impact Fc function [29] and negatively affect the stability of the antibody in vivo [30,31].

Recently, we have employed pyridazinediones (PDs) to functionally re-bridge the interchain disulfide bonds antibodies (PDs) bearing orthogonal 'clickable' handles into the native inter-strand disulfide bonds of trastuzumab full antibody [32-35]. By utilizing PDs harboring orthogonal 'clickable' handles, functional groups have been added to antibodies whilst retaining the covalent interchain linkage. This technology was then combined with mild bio-orthogonal conjugation of porphyrin photosensitizers and the conjugate targeted Her2 positive breast cancer cells [36,37].

In this study, we utilized lysine and disulfide modifications to identify an appropriate photo-immunoconjugate (PIC) for our suggested PIT. Briefly, a human anti-gp41 antibody (7B2) [38] was conjugated with two different photosensitizers, cationic porphyrin with a net charge of $3+$ and anionic IR700 with a net charge of 4-. We employed two different strategies for conjugation to the antibody; lysine conjugation by using phthalocyanine IRDye700DX dye [26], and "Click" conjugation by using an azide-bearing porphyrin with a strained alkyne attached via a disulfide bridge linker [27]. The comparison between PICs is of interest with regard to the dosimetry and solubility of PICs and mechanism of in vitro cytotoxicity (Figure 1A). 

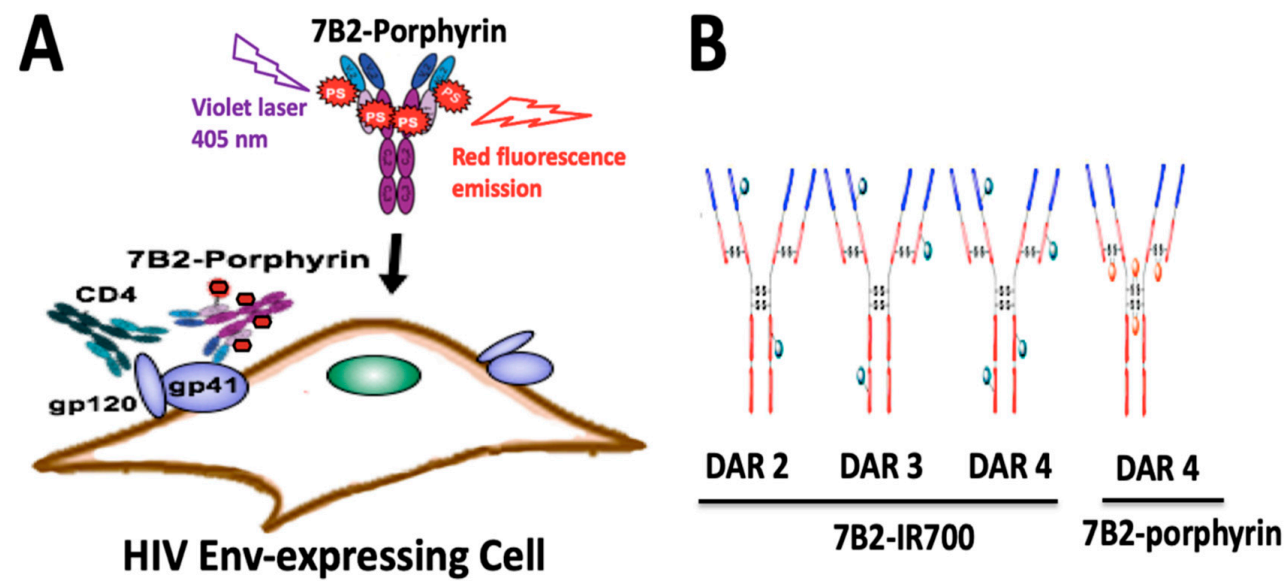

Figure 1. Structure and function of photo-immunoconjugates (PICs). (A) Anti-gp41 monoclonal antibody (7B2 MAb) conjugated with 4 porphyrins can specifically bind to the HIV infected cells expressing HIV Env (gp41 and gp120). The presence of CD4 may increase the binding ability of 7B2-porphyrin to the gp41 on the cell membrane. Porphyrins can be activated by visible light of a specific wavelength (herein $405 \mathrm{~nm}$ ) to initially generate singlet oxygen or ROS reaction, and consequently kill the target cell. Furthermore, the emission of red fluorescent by porphyrin can be observed during irradiation. (B) Schematic picture demonstrates two generations of PICs in the study; Lysine modification leading to heterogeneous IR700-PICs with "average distribution" of DARs 2, 3 and 4 with undefined physical and pharmacokinetic properties. In a click approach, disulfide re-bridging by a pyridazinedione construct yields a homogeneous porphyrin-PIC with a constant DAR4.

\section{Results and Discussion}

\subsection{Production and Characterization of Photoimmunoconjugates PICs}

Two generations of PICs were produced; Porphyrin-7B2 PIC was produced through the use of the strain-promoted azide-alkyne cycloaddition (SPAAC) methodology in two steps: firstly, the insertion of a strained alkyne harboring pyridazinediones (PD) into native interchain disulfide bonds in humanized IgG1 MAb (7B2), then, the antibody-alkyne reacted with azide-bearing water-soluble porphyrin.

As a side by side comparison, a well-known lysine-reactive and relatively hydrophilic dye, IRDye 700DX, in different molar concentrations, was covalently conjugated with primary amine groups on the structure of 7B2 MAb using a $N$-hydroxysuccinimide (NHS) ester of the photosensitizer (Figure 1B).

Chemical characterization by UV-Vis spectrophotometry showed a PD loading of 4.3 for the rebridged antibody and a DAR of 4.1 for the final porphyrin-PIC species. IR700-PICs showed DARs of 2.1, 3.0 and 4.4, which were equal to molar ratios of 3.5, 7, and 14, before conjugation, respectively (Figure 2A). The DLS results showed that the attachment of small molecule drugs to the 7B2 MAb slightly increases the molecule's average size (hydrodynamic radius, $\mathrm{R}_{\mathrm{h}}$ ) and polydispersity $(\% \mathrm{Pd})$, indicating the presence of some high molecular weight species in this region (Figure $2 \mathrm{~A}, \mathrm{D})$. 7B2-porphyrin showed the highest $\% \mathrm{Pd}$ and $\mathrm{R}_{\mathrm{h}}$ in the main peak. The zeta potential of 7B2 antibody changed very slightly from $+0.05 \mathrm{mV}$ towards +0.01 and -0.04 for cationic porphyrin and anionic IR-700 DAR4, respectively (Figure 2A). The binding of the 7B2 based-PICs to gp41 loop peptide antigen was examined within the conjugation. ELISA results showed that an increase of IR700-antibody-ratio decreases the binding ability, as 7B2-IR700 DAR4 showed the lowest binding to the gp41. In contrast, the conjugation of porphyrin with 7B2 MAb did not significantly affect the immunologic specificity of the antibody (Figure 2B). Results of microcapillary electrophoresis of non-reduced antibody ( $\mathrm{H}$ and L chains) and PICs demonstrated the molecular weights (MWs) with 151.4, 166.1 and $166.9 \mathrm{kDa}$ for naked antibody, rebridged antibody and clicked porphyrin-antibody. The increase in the MWs of 
IR700-PICs were in agreement of determined DARs, with 154.1, 154.7 and $156.8 \mathrm{kDa}$ for DARs 2, 3 and 4 , respectively (Figure 2A,C).

\begin{tabular}{|c|c|c|cc|c|}
\hline A & Immunoconjugate & $\begin{array}{c}\text { Fold-excess } \\
\text { of Drug per } \\
\text { Antibody }\end{array}$ & $\begin{array}{c}\text { Measured by } \\
\text { Spectrophotometer }\end{array}$ & Measured by DLS & $\begin{array}{c}\text { Measured by } \\
\text { Microcapillary }\end{array}$ \\
\cline { 3 - 6 } & Drug-Antibody Ratio & \%Pd & Radius (nm) & MW (kDa) \\
\hline 7B2 Antibody & - & 0 & 22.8 & 6.5 & 151.4 \\
7B2-IR700 DAR2 & 3.5 & 2.08 & 16.7 & 7.2 & 154.1 \\
7B2-IR700 DAR3 & 7 & 2.96 & 14.1 & 6.8 & 154.7 \\
7B2-IR700 DAR4 & 14 & 4.41 & 22.8 & 7.4 & 156.8 \\
7B2 Rebridged & 30 & 4.3 & 23.9 & 7.8 & 166.1 \\
7B2-porphyrin & 40 & 4.1 & 24.8 & 8.1 & 166.9 \\
\hline
\end{tabular}
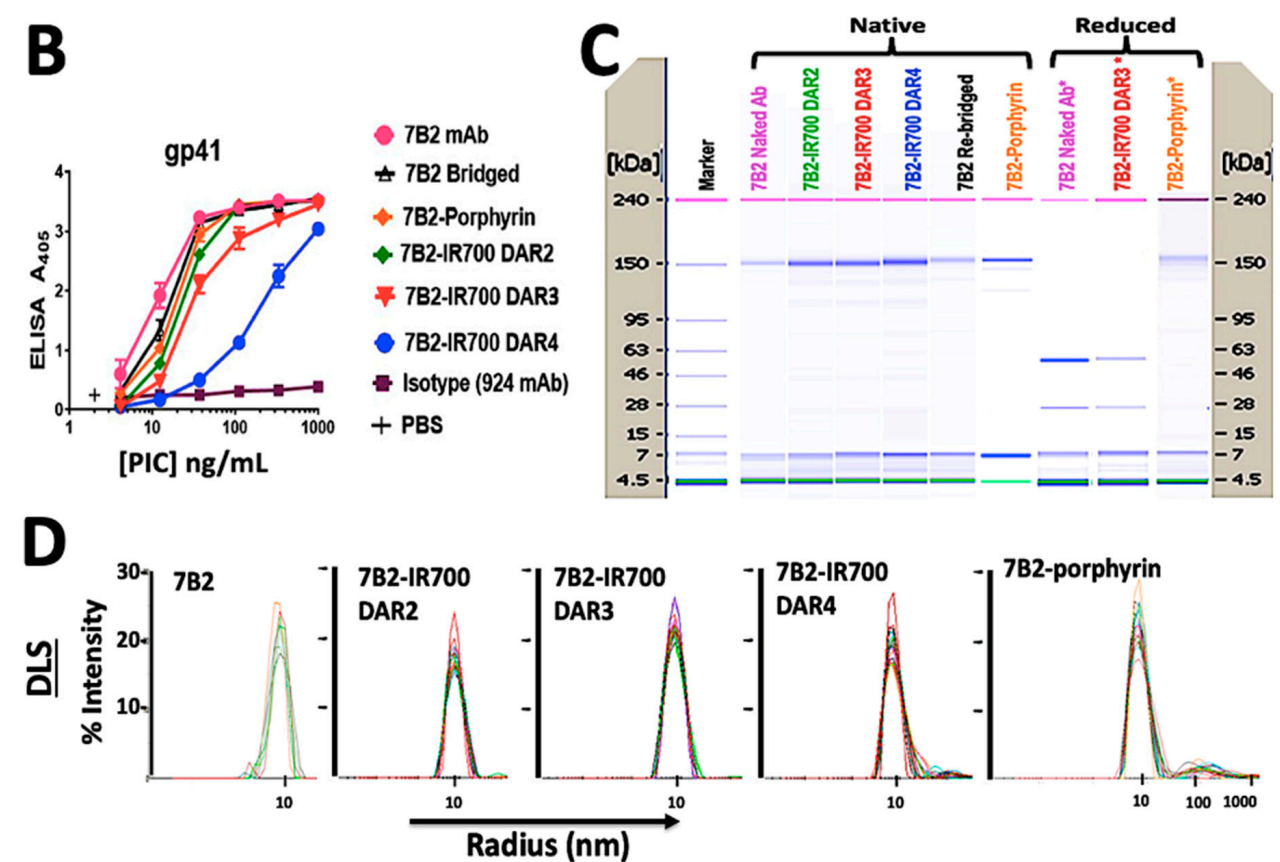

Figure 2. Characterization of photo-immunoconjugates (PICs). (A) The table shows products of 7B2 MAb conjugated with different molar concentrations of IR700, rebridged antibody with pyridazinedione and porphyrin. Chemical characterization by UV-Vis spectrophotometry shows the antibody to PS ratio (DAR). In DLS studies, the zeta potential ( $\zeta$ ) was estimated according to the Huckel equation. The increase in the molecular weights (MWs) of conjugations, measured by microcapillary electrophoresis, are in confirmation of determined DARs. (B) ELISA plates coated with gp41 antigen, as a peptide representing 7B2's epitope. Results are representative of means of triplicate values with three individual experiments. $924 \mathrm{MAb}$ was used as an isotype control. (C) Microcapillary electrophoresis of reduced and non-reduced 7B2 MAb and PICs, before and after irradiation. Unlike 7B2 and 7B2-IR700, the reduced 7B2-porphyrin did not show the separation of light and heavy chains, confirming the accuracy of click chemistry with DAR4. Size standards are indicated on the side of each "gel". (D) DLS Histograms of hydrodynamic radius $\left(R_{h}\right)$ for 7B2 MAb and PICs, monitoring how the $\mathrm{R}_{\mathrm{h}}$ preserved during the conjugation process. When IR700 was conjugated with an antibody molecule, ligand dissociation from IR700 affected the shape and solubility of the antibody to which it is attached as well as antibody-antigen complexes.

In the presence of reducing agent (TCEP), the light and heavy chains of either 7B2 or 7B2-IR700 were observed, due to the reduction of all available interchain disulfide bridges. The reduced 7B2-porphyrin did not show the separation of chains, confirming the accuracy of click chemistry with DAR4 (Figure 2C). 
In total, the characterization of PICs showed that the shape, solubility and binding ability of IR700-PICs was affected by increasing the drug-to-antibody ratio (DAR), while they were preserved for water-soluble homogeneous porphyrin-7B2 with a constant DAR of 4, due to the retention of rigid structural bridges on the antibody.

\subsection{Flow Cytometry Analysis}

By using a Cary Eclipse UV-Vis-NIR spectroscopy, we analyzed the excitation and emission spectra before flow cytometry study without using a secondary antibody. We showed the excitation of porphyrin by blue laser at $488 \mathrm{~nm}$ would not interfere with the emission intensity. The excitation by violet laser at $405 \mathrm{~nm}$ caused red emission at $725 \mathrm{~nm}$ with 1.163 (a. u.) intensity, while the maximum red fluorescent intensity (3.779 a. u.) can be observed by the excitation of Soret band of porphyrin at $432 \mathrm{~nm}$. The results were in agreement with the theoretical analysis of UV-Vis spectra (Supplementary Figure S1).

Specific cell binding to native Env was examined by flow cytometry. Without using a secondary antibody, the red fluorescent emission from IR700-PICs and porphyrin-PIC were directly detected on the Env-transfected cells, by filter Qdot 705 and filter Qdot 655, respectively (Figure 3A). By using FITC-secondary antibody, PICs showed equal binding ability into Env-transfected cells, while 7B2-IR700 DAR4 showed somewhat unspecific binding into the control 293T cells (Figure 3B). Not surprisingly, the presence of soluble $\mathrm{CD} 4$ (sCD4) showed a synergic effect on the binding ability of porphyrin-7B2, in comparison to the absence of $\mathrm{sCD} 4$ (Figure 3C). This result is in agreement with our previous studies on immunotoxins $[11,16]$, as we showed sCD4 enhances epitope exposure.

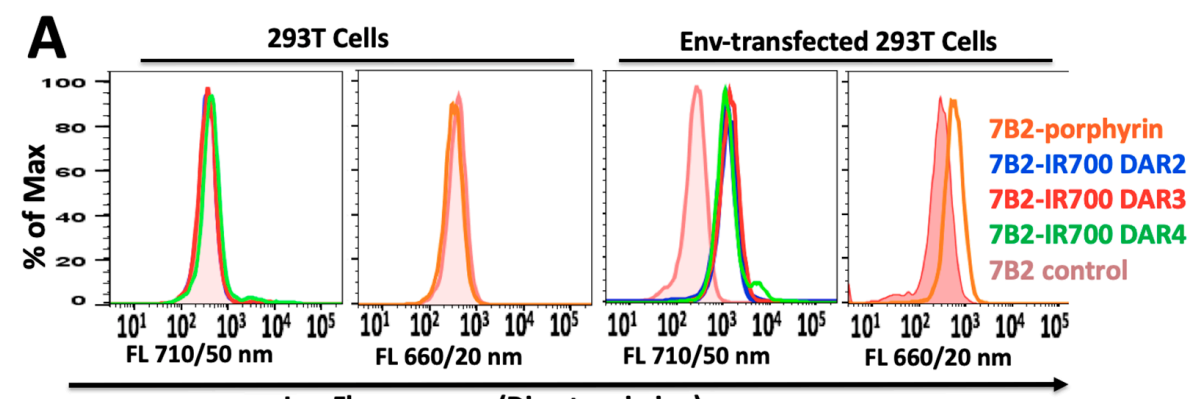

Log Fluorescence (Direct emission)

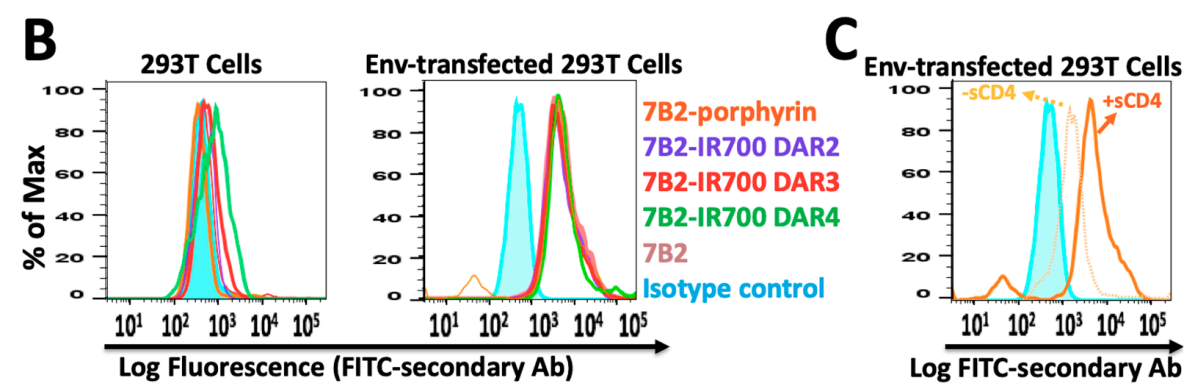

Figure 3. The flow cytometry histogram of PICs by using 293T control cells and Env-transfected 293T cells incubated in PBS $+1 \%$ BSA + sodium azide (0.2\%). (A) PIC binding to $293 \mathrm{~T}$ cells transfected with 92UG037.8 gp160 (293T/92UG) cells was directly detected through red fluorescent emission from IR700-PICs and porphyrin-PIC, by filter Qdot 705 and filter Qdot 655, respectively. (B) By using FITC-secondary immunofluorescence, PICs showed equal binding ability into Env-transfected cells, while 7B2-IR700 DAR4 showed somewhat unspecific binding into the control 293T cells. Results are representative of at least three independent experiments. Isotype control (chimeric RAC18) is shown as blue shaded histogram. (C) Studying the binding ability of porphyrin-7B2, in the presence and absence of soluble CD4 (sCD4). 
Interestingly, IR700-PICs with different DARs (Figure 2A) and different binding abilities (Figure 2B) showed equal fluorescence intensity, not only with the direct red emission by filter Qdot 705 (Figure 3A), also with indirect emission by FITC-secondary antibody (Figure 3B). This can be due to the quenching of chromophores, as some that are too close to each other will prevent the chromophores from being excited by laser light and then bleaching [39]. There is no linear relationship between the number of chromophores per antibody and fluorescence intensity [40], while there is a correlation between the trends in fluorescence quenching and efficacy of heterogeneous IR700-PICs [41]. We assume this quenching would not happen in homogeneous porphyrin-PIC with disulfide modification.

\subsection{ROS Generation}

In cellular studies, to have an equal irradiation for both porphyrin-PIC and IR700-PIC, for a side by side comparison, a custom-made LED device with a broad spectrum of light (380-780 nm) was utilized, as the blue spectra can excite the Soret band of porphyrin at $432 \mathrm{~nm}$, meanwhile, red spectra excites IR700-7B2 at $689 \mathrm{~nm}$ (Figure 4A).
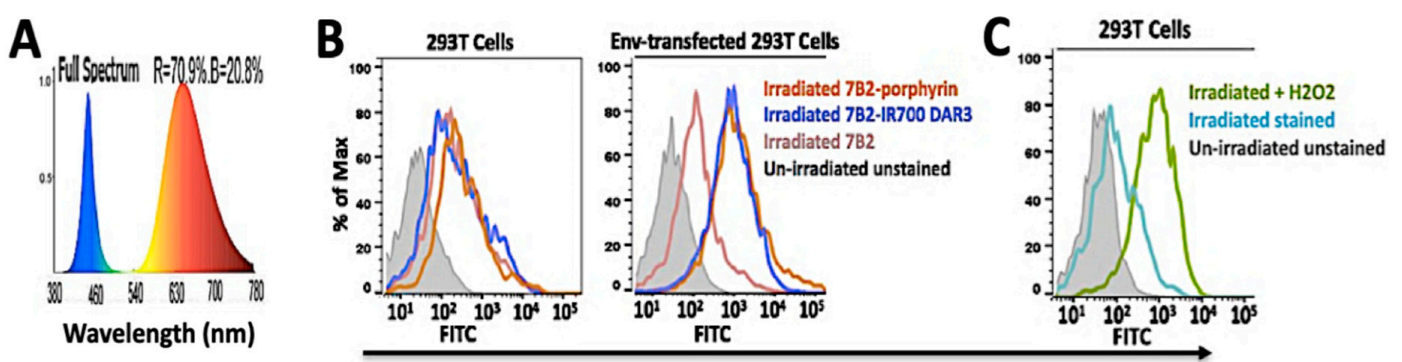

ROS Generation (DCF-DA)

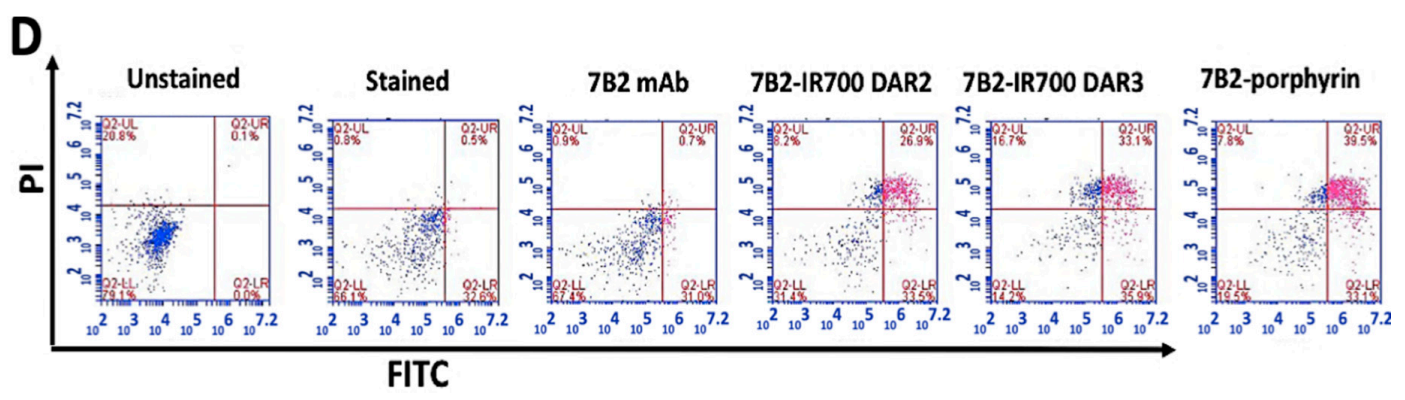

Figure 4. ROS generation and apoptosis assay by PICs. (A) The diagram demonstrates a broad spectrum of light $(380-780 \mathrm{~nm})$ by a homemade LED device $\left(30 \mathrm{~mW} / \mathrm{cm}^{2}\right)$ for irradiation of both IR700 and porphyrin PICs, at the same time. Blue spectra can excite the Soret band of porphyrin at $432 \mathrm{~nm}$, meanwhile red spectra excite 7B2-IR700 at $689 \mathrm{~nm}$. (B) Samples were kept in the dark (represented by grey) or were irradiated with $50 \mathrm{~J} / \mathrm{cm}^{2}$. (C) As a positive control, 293T cells were treated with $80 \mu \mathrm{M}$ $\mathrm{H} 2 \mathrm{O} 2$ for $24 \mathrm{~h}$ in dark. Control group (without $\mathrm{H} 2 \mathrm{O} 2$ ) was incubated under the same conditions. (D) In apoptosis assay by Annexin V - FITC/PI, the Env-transfected cells were incubated with PICs for $4 \mathrm{~h}$, then irradiated. PICs showed cell death due to late apoptosis (purple color in subset Upper Right) after $4 \mathrm{~h}$ incubation. Control 7B2 antibody showed neither cell death nor apoptosis sign. $(n=3)$.

To detect the ROS generation, the incubated cells by PICs and H2 DCF-DA fluorescent probe were irradiated with $50 \mathrm{~J} / \mathrm{cm}^{2}$. H2DCF-DA fluorescent probe was applied to detect ROS production in PIT-treated cells by using flow cytometry. The Env-transfected cells incubated with PICs exhibited a significant increase in ROS levels, whereas control 293T cells did not show ROS production (Figure 4B). In parallel, in the positive control group, we observed ROS production in 293T cells which were treated with $80 \mu \mathrm{M} \mathrm{H}_{2} \mathrm{O}_{2}$ for $24 \mathrm{~h}$ in the dark (Figure $4 \mathrm{C}$ ). The irradiated cells, with either no incubation or incubated with 7B2 antibody, showed an increase in the fluorescence intensity in comparison to the unstained cells in darkness. 


\subsection{Apoptosis Assay}

For apoptosis assays, the Env-transfected cells were incubated by PICs for $4 \mathrm{~h}$, irradiated, then Annexin V - FITC/PI dye added before flow cytometry analysis. No features related to early stages of apoptosis, such as extracellular exposure of phosphatidylserine, was observed in response to PICs (Figure 4D, purple color in the lower right subset). Both porphyrin-PIC and IR700-PIC showed cell death due to late apoptosis (FITC emission) after $4 \mathrm{~h}$ incubation, and signs of necrosis (PI emission). Control 7B2 antibody showed neither cell death nor signs of apoptosis (Figure 4D). The non-irradiated cells did not show sign of apoptosis.

\subsection{Photo-Cytotoxicity Assay}

Env-transfected $293 \mathrm{~T}$ cells (293 T/92UG) and control 293T cells were incubated with a serial dilution of PICs starting at $500 \mathrm{nM}$ in the presence of sCD4 (anti-gp120) for $4 \mathrm{~h}$ then were assayed by photoimmunotherapy (PIT) with $20 \mathrm{~J} / \mathrm{cm}^{2}$. IR700-PIC with a DAR of 3 appeared more cytotoxic than porphyrin-PIC with a constant DAR of 4 . PICs showed neither dark cytotoxicity on transfected cells nor nonspecific killing on 293T control cells. The cell growth inhibition was observed due to the irradiation on the cells without PIC treatment (green stars in Figure 5A).
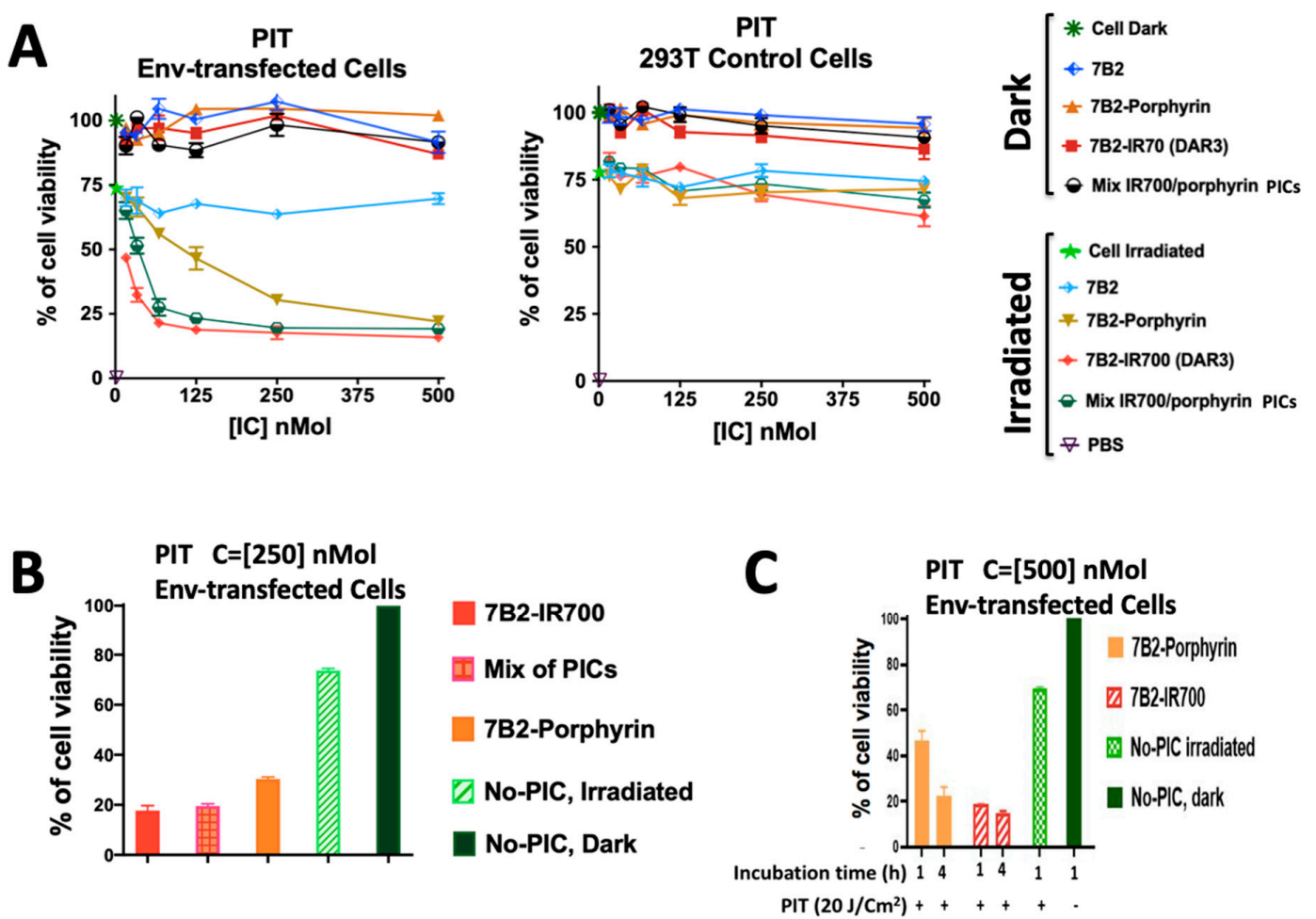

Figure 5. Comparing the photo-cytotoxicity and targeting of PICs by direct cytotoxicity assay. (A) Env-transfected $293 \mathrm{~T}$ cells (293 T/92UG) and control 293T cells were incubated with 7B2-IR700 (DAR 3), 7B2-porphyrin and an equal molarity mixture of both PICs in the presence of sCD4 (anti-gp120) for $4 \mathrm{~h}$ then were assayed by PIT. Data are \pm means S.E.M. $(n=3)$ with three individual experiments. Where no error bars are visible, they are obscured by the symbol. (B) An equal molarity mixture of porphyrin-PIC with IR700-PIC may increase the cytotoxicity in compare to porphyrin-PIC or the average cytotoxicity of both PICs. Data are \pm means S.E.M. $(n=3)$. (C) Incubation of transfected cells in two different times ( 1 and $4 \mathrm{~h}$ ) before PIT showed the internalization-dependency of Mab-porphyrin to have more photo-cytotoxicity, while the membrane binding of 7B2-IR700 was sufficient to induce cell death. Data are \pm means S.E.M. $(n=3)$.

As a prospect of this approach in an in vivo study, the doses of irradiation can be increased to maximum energy fluence of $100 \mathrm{~J} / \mathrm{cm}^{2}$, depending on the selected wavelength, however, visible light 
irradiation is unlikely to be toxic [42]. Optical microscopic observations before and after PIT demonstrated the bleb formation as signs of necrotic cell death. Cells PIT-treated with IR700-7B2 showed not only rapid bleb formation but also cell debris (Supplementary Figure S2).

To study how the combination of both PICs may affect the cytotoxicity, an equal molarity of porphyrin-PIC was mixed with IR700-PIC. Interestingly, this combination showed a significant increase in the cytotoxicity in compare to the average cytotoxicity of both PICs, due to the synergic effect of two PICs with two different mechanism (Figure 5A,B).

Furthermore, the photo-cytotoxicity of porphyrin-7B2 increased twice by increasing the time of incubation from $1 \mathrm{~h}$ to $4 \mathrm{~h}$, indicating the internalization-dependency of porphyrin-mAb. In contrast, the photo-cytotoxicity of IR700-7B2 did not change significantly on increasing the time of incubation at $37^{\circ} \mathrm{C}$ (Figure 5C).

\subsection{Confocal Microscopy Study}

The cells were treated with IR700-7B2 or 7B2-porphyrin for $1 \mathrm{~h}$, then washed and irradiated by 2-photons, $800 \mathrm{~nm}, 2.2 \mathrm{~mW} / \mathrm{cm}$. Red fluorescence emission from IR700-7B2 was directly detected (Figure 6A and Supplementary Video S1). As 7B2-porphyrin did not show strong red fluorescent emission, FITC anti-human IgG secondary antibody was applied to detect PIC indirectly (Figure 6B and Supplementary Video S2). After 10 min of adding porphyrin-7B2, the cellular swelling and bleb formation were observed as signs of necrotic cell death. The same necrotic signs were observed by adding IR700-7B2, but in 5 min of irradiation. After 30 min irradiation, Acridine Orange and Ethidium Bromide (AO/EB) were added as Live-dead dyes. Interestingly, the irradiated and non-irradiated regions were clearly distinguishable in red and green colors, respectively, confirming no dark toxicity by PICs (Figure 6C).

In conclusion, we compared the mechanism of two photosensitizers in the formation of PICs regarding the induction of cell death in HIV Env-transfected cells. We also addressed some of the main issues associated with conventional PDT including low selectivity, controlled drug dosimetry, dark toxicity and low water solubility of photosensitizer. Finally, we studied the possibility of PIT application to directly killing HIV-1 Env-expressing cells. Targeted phototoxicity seems to be primarily dependent on the binding of PS-antibody to the antigen on the cell membrane or HIV Envelope, whilst being independent of the PS type. Considering the fundamental restriction of light penetration, we suggest optimizing the excitation of PSs in deep tissue that may give us a highly flexible theranostic platform for HIV researches. This inevitably issue dictates the use of high-power irradiation [42]. The other alternatives for light delivery to the PICs in deep tissue could be the application of cellular-scale inorganic light-emitting diode ( $\mu$-ILED) arrays [43], or upconversion nanoparticles (UCNPs) in the field of PIT [44].

Approaches that focus on the combination of the PIT strategy with "shock and kill" technique could be a cornerstone of future research efforts towards an HIV cure [45]. The photo-cytotoxicity on the cell membrane triggered by the presence of HIV proteins can be an interesting to be proven strategy aiming the elimination of HIV latent reservoir in vivo. Previously, we observed different levels of surface HIV Env on the transfected and infected cells which may reflect differences due to laboratory-adapted versus clinical isolates [11]. However, it is still unclear how these discrepancies may relate to the expressed levels of HIV Env on the surface of HIV-infected cells, especially in the context of HIV-1 latency. We therefore recognize that further experimental killing approach on HIV-1 latently infected cells would add fundamental knowledge to the proposed PIT strategy. To the best of our knowledge, this is the first report to demonstrate the utility of photoimmunotherapy for HIV Env-expressing cells. The results of this strategy can potentially translate to viral photo-immunotherapy against other enveloped viruses. 


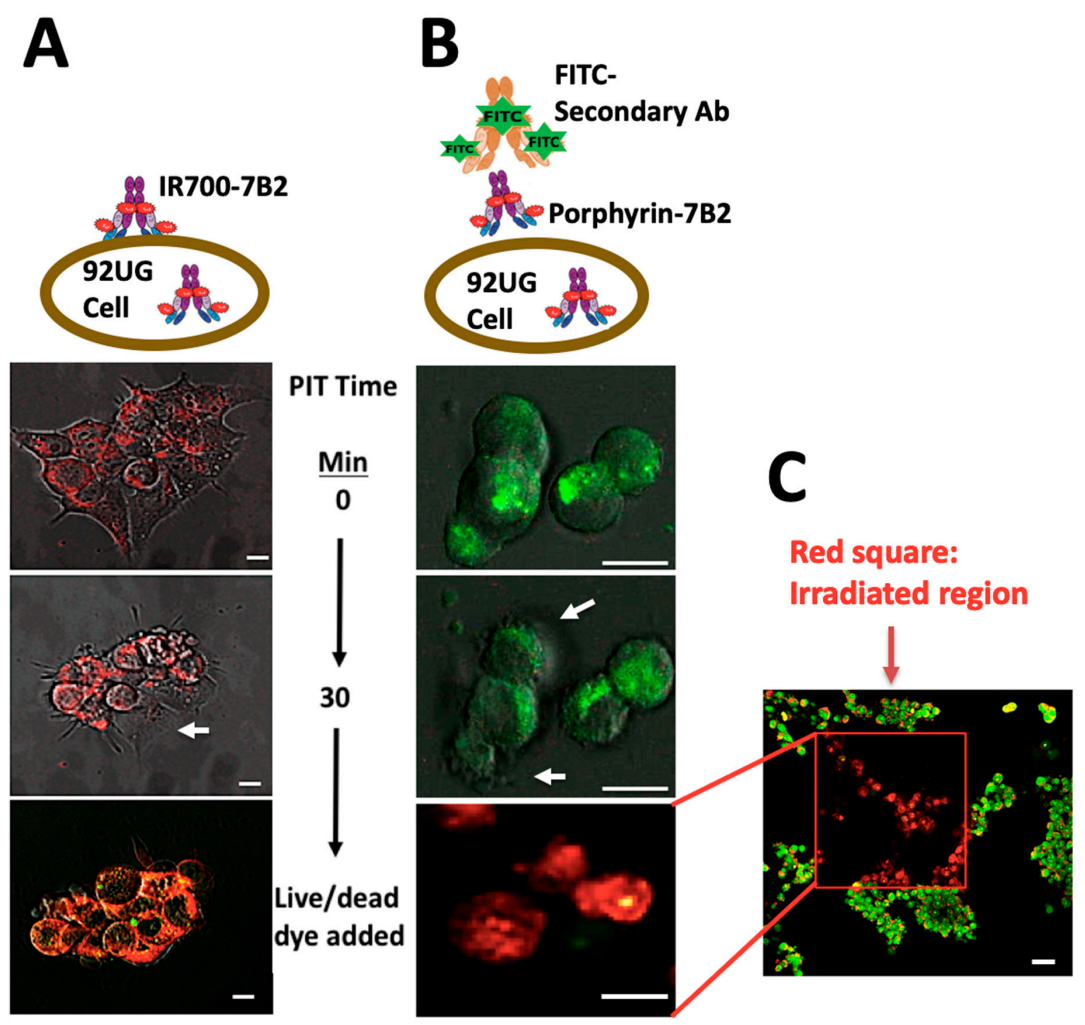

Figure 6. Target-specific cell death in response to PIT in HIV Env-expressing 293T cells. The cells were treated with IR700-7B2 (A) or 7B2-porphyrin (B) in the presence of SCD4 for $1 \mathrm{~h}$ before laser irradiation by microscope. (A) The emitted red fluorescent from IR700-7B2 was directly detected. (B) 7B2-porphyrin was detected indirectly by using FITC anti-human IgG secondary antibody. After 30 min irradiation, the cell viability was studied by using Acridine Orange and Ethidium Bromide (Live/dead dye). White arrows indicate the bleb formation caused the necrotic cell death. The white bar indicates $10 \mu \mathrm{m}$. (C) The red square shows the irradiated region that the cells are dead (red color). The non-irradiated region (green color) signifies live cells, confirming no dark toxicity by PIC. The white bar indicates $20 \mu \mathrm{m}$.

\section{Materials and Methods}

\subsection{Consumable Materials}

\subsubsection{Chemical Reagents}

All reagents are from ThermoFisher Scientific (Waltham, MA, USA) unless a statement to the contrary is made.

\subsubsection{Cell Lines}

293T/92UG cell lines stably express clade A clinical isolate 92UG037.8 gp160 as native trimers of HIV gp120/gp41. In this paper, Env-transfected cells refer to 293T/92UG cell lines [46], and HEK 293T cells refer to non-transfected control cells. The transfected and non-transfected 293T cells were incubated at $37^{\circ} \mathrm{C}$ in $5 \% \mathrm{CO}_{2}$ in DMEM medium with $10 \%$ fetal calf serum (Gibco Invitrogen, Grand Island, NY, USA).

\subsubsection{Antibodies}

MAb 7B2 (GenBank accession numbers JX188438 and JX188439) is an Anti-gp41 hIgG1 binding at amino acids 598-604 (CSGKLIC) in the helix-loop-helix region [38,47]. HY (Genbank accession numbers JX188440 and JX188441), is hIgG1/kappa, an affinity matured version of the anti-CD4 binding site $\mathrm{Ab}$ b12 [48]. MAbs were purified from supernatant media of hybridoma after passing Protein 
A agarose beads (Invitrogen, Carlsbad, CA, USA). Two types of soluble CD4 were utilized to study CD4-mediated effects [47]; CD4-IgG2 is a hIgG2 containing a tetrameric fusion protein in which the Fv portions of both $\mathrm{H}$ and $\mathrm{L}$ chains have been substituted by the V1 and V2 domains of hCD4. CD4-183 is a soluble fragment of human CD4 that binds the HIV gp120. Goat anti-human IgG (Invitrogen) was conjugated to either fluorescein isothiocyanate (FITC) or alkaline phosphatase (AP).

\subsection{Porphyrin-Antibody Conjugation by Click Chemistry}

Conjugation between azide porphyrin and mAb 7B2 was carried out in two steps: antibody functionalization, then click chemistry conjugation. The process is a modification of our protocol described previously $[35,49,50]$ and described in detail in the supplementary methods.

\subsection{Conjugation and Optimization of IR700-Antibody by Lysine Modification}

IRDye 700DX (IR700, LI-COR Biosciences, Lincoln, NE, USA) was covalently linked to purified $\mathrm{MAb} 7 \mathrm{~B} 2$ through an $\mathrm{N}$-hydroxysuccinimide reactive group, according to the manufacturer's instructions [26]. The process of conjugation and optimization are described in detail in the supplementary methods.

\subsection{UV-Vis Spectroscopy}

UV-Vis spectroscopy was used to measure protein concentrations and photosensitizer-antibody ratios (DAR), firstly by using Nanodrop 1000 UV-Visible spectrophotometer (ThermoFisher Scientific) and then a Cary 100 Bio UV-Visible spectrophotometer (Varian, CA, USA) operating at $21^{\circ} \mathrm{C}$. Blank was the sample buffer to correct base line with extinction coefficients; $\varepsilon_{280}=250,440 \mathrm{M}^{-1} \mathrm{~cm}^{-1}$ for antibodies, $\varepsilon_{335}=9100 \mathrm{M}^{-1} \mathrm{~cm}^{-1}$ for pyridazinedione scaffolds, $\varepsilon_{422}=165,175 \mathrm{M}^{-1} \mathrm{~cm}^{-1}$ for porphyrin and $\varepsilon_{689}=165,000 \mathrm{M}^{-1} \mathrm{~cm}^{-1}$ for IRDye 700DX. A Correction Factor at $280 \mathrm{~nm}$ of 0.25 (at $\mathrm{A}_{335}$ ) was applied for pyridazinedione scaffolds, as described elsewhere [36].

\subsection{Electrophoresis}

Molecular size, purity and accuracy of the conjugation of products were determined using Non/reducing glycine-SDS-PAGE and then confirmed by microcapillary electrophoresis in the presence or absence of TCEP. $\mathrm{HCl}(6.0 \mu \mathrm{L}, 20 \mathrm{mM}$ in d.d water, 12 eq.), as a reductive agent (Agilent Bioanalyzer, GE Healthcare, Piscataway, NJ, USA), following standard lab procedures.

\subsection{ELISA}

Purified MAbs and photo-immunoconjugates (PICs) were analyzed for antigen-binding specificity and titration by using ELISA, in wells coated with gp41 antigen $(1 \mu \mathrm{g} / \mathrm{mL})$, as described elsewhere [16]. The gp41 antigen is a linear peptide sequence [LGIWGCSGKLICTT] representing the epitope of MAb 7B2. AP-conjugated secondary antibody (goat anti-human IgG) (Zymed Laboratories, South San Francisco, CA, USA) were used to detect the primary antibodies binding to the antigen. Data are represented as optical density at $405 \mathrm{~nm}$ and signify means of triplicate values with three independent experiments.

\subsection{Dynamic Light Scattering (DLS) and Zeta Potential}

Hydrodynamic radii, electrophoretic mobility, zeta potential, and polydispersity of naked antibody and PICs were measured. Samples with $70 \mu \mathrm{L}$ volume at $1 \mathrm{mg} / \mathrm{mL}$ in UV-transparent 96-well plates were measured by using a DLS Wyatt Möbius (Wyatt Technologies, Dernbach, Germany) with incident light at $532 \mathrm{~nm}$, at an angle of $163.5^{\circ}$. Samples were equilibrated at $25 \pm 0.1{ }^{\circ} \mathrm{C}$ for $600 \mathrm{~s}$ before the measurements, with the constant temperature during the experiments. All samples represent triplicate values with 10 acquisitions and a $5 \mathrm{~s}$ acquisition time. The change in cumulant fitted hydrodynamic radius in nanometers was tracked throughout the storage period. Results were analyzed using the 
Dynamics software version 7.1.7 (Wyatt Technologies, Santa Barbara, CA, USA). By using an Agilent Technologies Cary 5000 Cary Series UV-VIS-NIR spectrofluorimeter, we showed the incident laser beam at $532 \mathrm{~nm}$ is not within the fluorescent sample's (IR700-7B2 and porphyrin-7B2) band of excitation; as the analysis would not be disrupted or tainted.

\subsection{Direct and Indirect Immunofluorescence Using Flow Cytometry}

Direct and indirect immunofluorescence were applied using flow cytometry to analyze the binding of photo-immunoconjugates (PICs) to Env-transfected 293T cells. $8 \times 10^{4}$ cells were incubated with PBS/BSA/0.01\% sodium azide (PBA) for $30 \mathrm{~min}$ in RT, and then PICs added to reach the final concentrations of $10 \mu \mathrm{g} / \mathrm{mL}$ in the presence of $5 \mu \mathrm{g} / \mathrm{mL}$ soluble CD4. Cells were incubated with PICs for $1 \mathrm{~h}$ at room temperature. For indirect assay, half of the samples were washed, and then stained with FITC conjugated goat anti-human IgG secondary antibody $(2 \mu \mathrm{g} / \mathrm{mL})$ for $1 \mathrm{~h}$. All the samples, for direct and indirect assays, were washed twice and fixed in $100 \mu \mathrm{L}$ of $2 \%$ paraformaldehyde. After $4 \mathrm{~h}$, $150 \mu \mathrm{L}$ of PBS was added to the samples. Cells with 10,000 events were evaluated on BD LSRFortessa (Becton-Dickson, Mountain View, CA, USA), analyzed by Flow-Jo software version 7.5 (Tree Star Inc., Ashland, OR, USA). Mean fluorescence of the gated cell population labelled with immunoconjugate was calculated in relation to the mean fluorescence of cells labelled with MAb 7B2.

Direct immunofluorescence without adding FITC conjugated secondary antibody was applied to analyze the binding of PICs to Env-transfected 293T cells. For IR700-PICs, the cells were excited by either violet laser at $405 \mathrm{~nm}$ or red laser at $640 \mathrm{~nm}$, and the red fluorescence emission was detected by $710 \pm 50$ band-pass filter (Qdot 705). For porphyrin-PICs, the cells were excited by violet laser at $405 \mathrm{~nm}$, and the red fluorescence emission was detected by $660 \pm 20$ band-pass filter (Qdot 655).

\subsection{ROS Detection}

ROS generation in the cell lines was detected with the fluorescent probe H2DCF-DA ( $2^{\prime}, 7^{\prime}$-dichlorodihydrofluorescein diacetate). $2 \times 10^{5}$ cells were incubated with $1 \mu \mathrm{M}$ of native antibody, porphyrin-PIC, or IR700-PIC in 96 well plates in phenol-free DMEM for $45 \mathrm{~min}$. The cells were washed and incubated with $1 \mu \mathrm{M}$ H2DCF-DA solution prepared in PBS, and washed again and incubated with phenol-free DMEM before irradiation with $50 \mathrm{~J} / \mathrm{cm}^{2}$. A mirror dark-plate, submitted to the same procedure, except for light exposure, contained the dark control groups. The cells incubated with $40 \mathrm{mM}$ $\mathrm{H}_{2} \mathrm{O}_{2}$, without irradiation, were used as positive control. Fluorescence intensity $(\mathrm{Ex} / \mathrm{Em}=485 / 535 \mathrm{~nm})$ was measured with the flow cytometry, with the procedure as mentioned above.

\subsection{Apoptosis/Cell Death Assay}

Annexin V-FITC/PI cell staining was performed following $6 \mathrm{~h}$ of standard photoimmunotherapy. Briefly, cells were incubated with Annexin V binding buffer (10 mM HEPES, pH 7.4; $2.5 \mathrm{mM} \mathrm{CaCl}_{2}$; $140 \mathrm{mM} \mathrm{NaCl}$ ) and stained with recombinant annexin $\mathrm{V}$ conjugated to green-fluorescent FITC dye (ThermoFisher Scientific, San Jose, CA, USA) for $15 \mathrm{~min}$. After three washes, cells were incubated with $2 \mu \mathrm{g} / \mathrm{mL}$ of propidium iodide (PI) (Life Technologies, Carlsbad, CA, USA) for $15 \mathrm{~min}$. The mean fluorescence intensity was measured for 10,000 events. The data were collected using linear amplification for two optical detectors, FSC and SSC, and log amplification for related filters, and analyzed by associated software as mentioned above.

\subsection{Photo-Cytotoxicity Assay}

Naked 7B2 antibody, IR700-7B2, porphyrin-7B2 and a mixture of both PICs with equal molarity were diluted in the phenol-free DMEM medium, but without FCS, to reach a range of five final concentrations of $500 \mathrm{nM}, 250 \mathrm{nM}, 125 \mathrm{nM}, 62.5 \mathrm{nM}$ and $31.2 \mathrm{nM}$ into 5 wells of a 96-well plate. HIV Env-transfected cells and 293T cells were adjusted to a concentration of $1 \times 10^{6}$ cells $/ \mathrm{mL}$. Soluble CD4 was added to each well in a final concentration of $500 \mathrm{ng} / \mathrm{mL}$. The plate incubated for $4 \mathrm{~h}$ at $37^{\circ} \mathrm{C}$ and $5 \% \mathrm{CO}_{2}$. Identical plates were kept protected from light for the same period 
to obtain the proper dark control groups. Afterwards, the cells were washed with a $4 \mathrm{X}$ excess of phenol-free serum-free DMEM to remove any unbound PICs. The plates were irradiated with $20 \mathrm{~J} / \mathrm{cm}^{2}$ of light $(380-780 \mathrm{~nm})$ by a homemade LED array $\left(30 \mathrm{~mW} / \mathrm{cm}^{2}\right)$ in two equal doses separated by $10 \mathrm{~min}$, as described elsewhere [51,52]. After irradiation, $10 \mu \mathrm{L}$ of FCS was added to each well and the plates were kept in the incubator for 3 days. The cell growth in each group was also monitored and imaged under a microscope (IX81, Olympus America, Center Valley, PA, USA) at each time point, before and after irradiation. MTS/PMS substrate (Promega, Madison, WI, USA) was added to cultures and absorbance at $490 \mathrm{~nm}$ was recorded at $1-4 \mathrm{~h}$ of incubation. Results represent the mean and SEM of triplicate samples for three independent experiments, and plotted as $\mathrm{A}_{490}$ with a subtraction from background. Data are represented as \% of cell viability versus PIC concentration.

\subsection{Live Imaging by Two-Photon Confocal Microscopy}

Live cell imaging was performed using an inverted LSM 780 multiphoton laser scanning confocal microscope (Zeiss, Jena, Germany) equipped with a Chameleon laser (Ti:sapphire, Coherent, Santa Clara, CA, USA) as a source for two-photons (2P) excitation at $800 \mathrm{~nm}$. The images were obtained by the average of 2 scans and no appreciate variation was observed. The spatial resolution was approximately $350 \mathrm{~nm}$ considering the numerical aperture and the excitation wavelength, as described previously [53]. The occurrence of cell death (irradiated region) was compared with live cells (non-irradiated region) by acridine orange-ethidium bromide (AO/EB) double-staining. Detailed conditions and settings are described in the supplementary methods.

\subsection{Statistical Analyses}

Statistical analyses were performed with GraphPad Prism version 8.0 (GraphPad Software, San Diego, CA, USA). Data are shown as mean and standard error of mean (SEM) of the indicated number of replicate values. If no error bar appears signifying that the error bars are smaller than, and obscured by, the symbol. The unpaired two-tailed Student's t-test was applied for statistical comparison, unless specifically stated otherwise.

\subsection{Data Availability}

All data generated or analyzed during this research are included in this published article and its Supplementary Information file. The detailed method of live microscopy with extra videos can be found at https://docs.google.com/forms/d/e/1FAIpQLSdOC3q1uWNIpVj_iPcz5G8rLrQRjuffNowE2UDcUrKI3C_Aw/viewform?usp=sf_link. Password:USP4030.

Supplementary Materials: Supplementary materials can be found at http://www.mdpi.com/1422-0067/21/23/ 9151/s1.

Author Contributions: F.E.G.G. and M.S. wrote the main manuscript text and prepared figures. F.E.G.G., R.W.B., V.C. and M.S. designed and performed the biochemical, immunological and microscopy experiments. R.S.D., E.F.d.C., M.S. and L.M.R.J. designed and performed the viral assays. C.B. performed the small molecule synthesis and performed the bioconjugation experiments. F.E.G.G. and V.C. supervised the study. All authors reviewed the manuscript. All authors have read and agreed to the published version of the manuscript.

Funding: The authors acknowledge the support provided by: FAPESP (Sao Paulo Research Foundation) - grant numbers: 2017/10910-5 (M. Sadraeian-Pós-Doutorado-Fluxo Contínuo), 2013/07276-1(CEPOF-CEPID Program), 2009/54035-4 (EMU). The reagents related to HIV were supported by NIH AIDS Research and Reference Reagent Program. We also gratefully acknowledge the Leverhulme Trust (RPG-2020-010) for funding C.B.

Acknowledgments: We also thank NIH AIDS Research and Reference Reagent Program for supporting the reagent related to HIV. We thank Seth Pincus, for his supports in the Department of Chemistry and Biochemistry, Montana State University, Bozeman, MT. We thank Juliana Galinskas (Unifesp) and Bruno Andrade Ono (IFSC) for their valuable expertise in quantification assay and fluorescence microscopy, respectively.

Conflicts of Interest: V.C. is a Director of ThioLogics. Other authors declare no competing interests. 


\section{Abbreviations}

$\begin{array}{ll}\text { DAR } & \text { Drug-Antibody-Ratio } \\ \text { MAb } & \text { Monoclonal Antibody } \\ \text { PDT } & \text { Photodynamic Therapy } \\ \text { PIT } & \text { Photoimmunotherapy } \\ \text { PIC } & \text { Photo-immunoconjugate }\end{array}$

\section{References}

1. Caskey, M.; Klein, F.; Nussenzweig, M.C. Broadly neutralizing anti-HIV-1 monoclonal antibodies in the clinic. Nat. Med. 2019, 25, 547-553. [CrossRef] [PubMed]

2. Polito, L.; Bortolotti, M.; Battelli, M.G.; Calafato, G.; Bolognesi, A. Ricin: An ancient story for a timeless plant toxin. Toxins 2019, 11, 324. [CrossRef] [PubMed]

3. Larson, S.M.; Carrasquillo, J.A.; Cheung, N.K.V.; Press, O.W. Radioimmunotherapy of human tumours. Nat. Rev. Cancer 2015, 15, 347-360. [CrossRef] [PubMed]

4. Helal, M.; Dadachova, E. Radioimmunotherapy as a Novel Approach in HIV, Bacterial, and Fungal Infectious Diseases. Cancer Biother. Radiopharm. 2018, 33, 330-335. [CrossRef]

5. Ventola, C.L. Cancer Immunotherapy, Part 3: Challenges and Future Trends. Pharm. Ther. 2017, 42, 514-521.

6. Biteghe, F.A.N.; Chalomie, N.E.T.; Mungra, N.; Vignaux, G.; Gao, N.; Vergeade, A.; Okem, A.; Naran, K.; Ndong, J.C.; Barth, S. Antibody-based immunotherapy: Alternative approaches for the treatment of metastatic melanoma. Biomedicines 2020, 8, 327. [CrossRef]

7. Ferrari, G.; Haynes, B.F.; Koenig, S.; Nordstrom, J.L.; Margolis, D.M.; Tomaras, G.D. Envelope-specific antibodies and antibody-derived molecules for treating and curing HIV infection. Nat. Rev. Drug Discov. 2016, 15, 823-834. [CrossRef]

8. Tsukrov, D.; Dadachova, E. The potential of radioimmunotherapy as a new hope for HIV patients. Expert. Rev. Clin. Immunol. 2014, 10, 553-555. [CrossRef]

9. Pincus, S.H.; Song, K.; Maresh, G.A.; Hamer, D.H.; Dimitrov, D.S.; Chen, W.; Zhang, M.Y.; Ghetie, V.F.; Chan-Hui, P.Y.; Robinson, J.E.; et al. Identification of Human Anti-HIV gp160 Monoclonal Antibodies That Make Effective Immunotoxins. J. Virol. 2017, 91, e01955-16. [CrossRef]

10. Sadraeian, M. Production and Characterization of Pulchellin A Chain Conjugated to HIV mAbs, and Study Its Selective Cytotoxicity Against Cells Expressing HIV Envelope. Ph.D. Thesis, Universidade de São Paulo, São Carlos, Brazil, 2017.

11. Sadraeian, M.; Guimarães, F.E.G.; Araújo, A.P.U.; Worthylake, D.K.; LeCour, L.J.; Pincus, S.H. Selective cytotoxicity of a novel immunotoxin based on pulchellin A chain for cells expressing expressing HIV envelope. Sci. Rep. 2017, 7, 7579. [CrossRef]

12. Sadraeian, M.; Mansoorkhani, M.J.K.; Mohkam, M.; Rasoul-Amini, S.; Hesaraki, M.; Ghasemi, Y. Prevention and Inhibition of TC-1 Cell Growth in Tumor Bearing Mice by HPV16 E7 Protein in Fusion with Shiga Toxin B-Subunit from shigella dysenteriae. Cell J. 2013, 15, 176-181. [PubMed]

13. Med, A.N.; Hanaoka, Y.H.H. Applying near-infrared photoimmunotherapy to B-cell lymphoma: Comparative evaluation with radioimmunotherapy in tumor xenografts. Ann. Nucl. Med. 2017, 31, 669-677.

14. Sandland, J.; Boyle, R.W. Photosensitizer Antibody-Drug Conjugates: Past, Present, and Future. Bioconjug. Chem. 2019, 30, 975-993. [CrossRef] [PubMed]

15. Pincus, S.H.; Song, K.; Maresh, G.A.; Frank, A.; Worthylake, D.; Chung, H.; Polacino, P.; Hamer, D.H.; Coyne, C.P.; Rosenblum, M.G.; et al. Design and In Vivo Characterization of Immunoconjugates Targeting HIV gp160. J. Virol. 2017, 91, e01360-16. [CrossRef]

16. Craig, R.B.; Summa, C.M.; Corti, M.; Pincus, S.H. Anti-HIV Double Variable Domain Immunoglobulins Binding Both gp41 and gp120 for Targeted Delivery of Immunoconjugates. PLoS ONE 2012, 7, 1-13. [CrossRef]

17. Buzzá, H.H.; Silva, A.P.D.; Vollet Filho, J.D.; Ramirez, D.P.; Trujillo, J.R.; Inada, N.M.; Moriyama, L.T.; Kurachi, C.; Bagnato, V.S. Photodynamic therapy: Progress toward a scientific and clinical network in Latin America. Photodiagnosis Photodyn. Ther. 2016, 13, 261-266. [CrossRef]

18. Wainwright, M.; O'Kane, C.; Rawthore, S. Phenothiazinium photosensitisers XI. Improved toluidine blue photoantimicrobials. J. Photochem. Photobiol. B Biol. 2016, 160, 68-71. [CrossRef] 
19. Auwärter, W.; Écija, D.; Klappenberger, F.; Barth, J.V. Porphyrins at interfaces. Nat. Chem. 2015, 7, $105-120$. [CrossRef]

20. Fujita, A.K.L.; Rodrigues, P.G.S.; Requena, M.B.; Escobar, A.; da Rocha, R.W.; Nardi, A.B.; Kurachi, C.; de Menezes, P.F.; Bagnato, V.S. Fluorescence evaluations for porphyrin formation during topical PDT using ALA and methyl-ALA mixtures in pig skin models. Photodiagnosis Photodyn. Ther. 2016, 15, 236-244. [CrossRef]

21. Valkov, A.; Nakonechny, F.; Nisnevitch, M. Polymer-immobilized photosensitizers for continuous eradication of bacteria. Int. J. Mol. Sci. 2014, 15, 14984-14996. [CrossRef]

22. Nakonechny, F.; Barel, M.; David, A.; Koretz, S.; Litvak, B.; Ragozin, E.; Etinger, A.; Livne, O.; Pinhasi, Y.; Gellerman, G.; et al. Dark antibacterial activity of rose Bengal. Int. J. Mol. Sci. 2019, 20, 3196. [CrossRef] [PubMed]

23. Dougherty, T.J.; Gomer, C.J.; Henderson, B.W.; Jori, G.; Kessel, D. Photodynamic Therapy. J. Natl. Cancer Inst. 1998, 17, 889-905. [CrossRef] [PubMed]

24. Bacellar, I.O.L.; Tsubone, T.M.; Pavani, C.; Baptista, M.S. Photodynamic efficiency: From molecular photochemistry to cell death. Int. J. Mol. Sci. 2015, 16, 20523-20559. [CrossRef] [PubMed]

25. Crous, A.; Abrahamse, H. Effective gold nanoparticle-antibody-mediated drug delivery for photodynamic therapy of lung cancer stem cells. Int. J. Mol. Sci. 2020, 21, 3742. [CrossRef] [PubMed]

26. Caudle, A.S.; Yang, W.T.; Mittendorf, E.A.; Kuerer, H.M. Cancer Cell-Selective In Vivo Near Infrared Photoimmunotherapy Targeting Specific Membrane Molecules. Nat. Med. 2016, 150, 137-143.

27. Bryden, F.; Maruani, A.; Savoie, H.; Chudasama, V.; Smith, M.E.B.; Caddick, S.; Boyle, R.W. Regioselective and stoichiometrically controlled conjugation of photodynamic sensitizers to a HER2 targeting antibody fragment. Bioconjug. Chem. 2014, 25, 611-617. [CrossRef] [PubMed]

28. Maruani, A.; Smith, M.E.B.; Miranda, E.; Chester, K.A.; Chudasama, V.; Caddick, S. A plug-and-play approach to antibody-based therapeutics via a chemoselective dual click strategy. Nat. Commun. 2015, 6, 1-9. [CrossRef] [PubMed]

29. Bahou, C.; Love, E.A.; Leonard, S.; Spears, R.J.; Maruani, A.; Armour, K.; Baker, J.R.; Chudasama, V. Disulfide Modified IgG1: An Investigation of Biophysical Profile and Clinically Relevant Fc Interactions. Bioconjug. Chem. 2019, 30, 1048-1054. [CrossRef] [PubMed]

30. Chester, K.A.; Baker, R.; Caddick, S. Next generation maleimides enable the controlled assembly. R. Soc. Chem. 2014, 10, 1-52.

31. Jackson, D.Y. Processes for Constructing Homogeneous Antibody Drug Conjugates. Org. Process. Res. Dev. 2016, 20, 852-866. [CrossRef]

32. Bryden, F.; Boyle, R.W. A mild, facile, one-pot synthesis of zinc azido porphyrins as substrates for use in click chemistry. Synlett. 2013, 24, 1978-1982.

33. Cheng, M.H.Y.; Maruani, A.; Savoie, H.; Chudasama, V.; Boyle, R.W. Synthesis of a novel HER2 targeted aza-BODIPY-antibody conjugate: Synthesis, photophysical characterisation and: In vitro evaluation. Org. Biomol. Chem. 2018, 16, 1144-1149. [CrossRef] [PubMed]

34. Lee, M.T.W.; Maruani, A.; Richards, D.A.; Baker, J.R.; Caddick, S.; Chudasama, V. Enabling the controlled assembly of antibody conjugates with a loading of two modules without antibody engineering. Chem. Sci. 2017, 8, 2056-2060. [CrossRef] [PubMed]

35. Castañeda, L.; Wright, Z.V.F.; Marculescu, C.; Tran, T.M.; Chudasama, V.; Maruani, A.; Hull, E.A.; Nunes, J.P.; Fitzmaurice, R.J.; Smith, M.E.; et al. A mild synthesis of N-functionalised bromomaleimides, thiomaleimides and bromopyridazinediones. Tetrahedron Lett. 2013, 54, 3493-3495. [CrossRef] [PubMed]

36. Robinson, E.; Nunes, J.P.M.; Vassileva, V.; Maruani, A.; Nogueira, J.C.F.; Smith, M.E.B.; Pedley, B.; Caddick, S.; Baker, J.R.; Chudasana, V. Pyridazinediones deliver potent, stable, targeted and efficacious antibody-drug conjugates (ADCs) with a controlled loading of 4 drugs per antibody. RSC Adv. 2017, 7, 9073-9077. [CrossRef]

37. Bryden, F.; Maruani, A.; Rodrigues, J.M.M.; Cheng, M.H.Y.; Savoie, H.; Beeby, A.; Chudasana, V.; Boyle, R.W. Assembly of High-Potency Photosensitizer-Antibody Conjugates through Application of Dendron Multiplier Technology. Bioconjug. Chem. 2018, 29, 176-181. [CrossRef]

38. Pincus, S.H.; Fang, H.; Wilkinson, R.A.; Marcotte, T.K.; Robinson, J.E.; Olson, W.C. In vivo efficacy of anti-glycoprotein 41 , but not anti-glycoprotein 120, immunotoxins in a mouse model of HIV infection. J. Immunol. 2003, 170, 2236-2241. [CrossRef]

39. Kobayashi, H.; Choyke, P.L. Target-Cancer-Cell-Specific Activatable Fluorescence Imaging Probes: Rational Design and in Vivo Applications. Acc. Chem. Res. 2011, 44, 83-90. [CrossRef] 
40. Kratochvil, H.T.; Ha, D.G.; Zanni, M.T. Counting tagged molecules one by one: Quantitative photoactivation and bleaching of photoactivatable fluorophores. J Chem Phys. 2015, 143, 104201. [CrossRef]

41. Fujimura, D.; Inagaki, F.; Okada, R.; Rosenberg, A.; Furusawa, A.; Choyke, P.L.; Kobayashi, H. Conjugation Ratio, Light Dose, and pH Affect the Stability of Panitumumab-IR700 for Near-Infrared Photoimmunotherapy. ACS Med. Chem. Lett. 2020, 11, 1598-1604. [CrossRef]

42. Pires, L.; Demidov, V.; Wilson, B.C.; Salvio, A.G.; Moriyama, L.; Bagnato, V.S.; Vitkin, I.A.; KurachI, C. Dual-agent photodynamic therapy with optical clearing eradicates pigmented melanoma in preclinical tumor models. Cancers 2020, 12, 1956. [CrossRef] [PubMed]

43. Jeong, J.W.; McCall, J.G.; Shin, G.; Zhang, Y.; Al-Hasani, R.; Kim, M.; Li, S.; Sim, J.Y.; Jang, K.I.; Shi, Y.; et al. Wireless Optofluidic Systems for Programmable In Vivo Pharmacology and Optogenetics. Cell 2015, 162, 662-674. [CrossRef] [PubMed]

44. Ramírez-García, G.; Panikar, S.S.; López-Luke, T.; Piazza, V.; Honorato-Colin, M.A.; Camacho-Villegas, T.; Hernández-Gutiérrez, R.; De la Rosa, E. An immunoconjugated up-conversion nanocomplex for selective imaging and photodynamic therapy against HER2-positive breast cancer. Nanoscale 2018, 10, 10154-10165. [CrossRef] [PubMed]

45. Dashti, A.; Waller, C.; Mavigner, M.; Schoof, N.; Bar, K.J.; Shaw, G.M.; Vanderford, T.H.; Liang, S.; Lifson, J.D.; Dunham, R.M.; et al. SMAC Mimetic Plus Triple-Combination Bispecific HIVxCD3 Retargeting Molecules in SHIV.C.CH505-Infected, Antiretroviral Therapy-Suppressed Rhesus Macaques. J. Virol. 2020, 94, e00793-20. [CrossRef]

46. Kovacs, J.M.; Noeldeke, E.; Ha, H.J.; Peng, H.; Rits-Volloch, S.; Harrison, S.C.; Chen, B. Stable, uncleaved HIV-1 envelope glycoprotein gp140 forms a tightly folded trimer with a native-like structure. Proc. Natl. Acad. Sci. USA 2014, 111, 18542-18547. [CrossRef]

47. Pincus, S.H.; McClure, J. Soluble CD4 enhances the efficacy of immunotoxins directed against gp41 of the human immunodeficiency virus. Proc. Natl. Acad. Sci. USA 1993, 90, 332-336. [CrossRef]

48. Mchugh, L.; Hu, S.; Lee, B.K.; Santora, K.; Kennedy, P.E.; Berger, E.A.; Pastan, I.; Hamer, D.H. Increased Affinity and Stability of an Anti-HIV-1 Envelope Immunotoxin by Structure-based Mutagenesis. J. Biol. Chem. 2002, 277, 34383-34390. [CrossRef]

49. Giuntini, F.; Bryden, F.; Daly, R.; Scanlan, E.M.; Boyle, R.W. Huisgen-based conjugation of water-soluble porphyrins to deprotected sugars: Towards mild strategies for the labelling of glycans. Org. Biomol. Chem. 2014, 12, 1203-1206. [CrossRef]

50. Bahou, C.; Richards, D.A.; Maruani, A.; Love, E.A.; Javaid, F.; Caddick, S.; Baker, J.R.; Chudasama, V. Highly homogeneous antibody modification through optimisation of the synthesis and conjugation of functionalised dibromopyridazinediones. Org. Biomol. Chem. 2018, 16, 1359-1366. [CrossRef]

51. Inada, N.M.; da Costa, M.M.; Guimarães, O.C.C.; Ribeiro, E.d.S.; Kurachi, C.; Quintana, S.M.; Lombardi, W.; Bagnato, V.S. Photodiagnosis and treatment of condyloma acuminatum using 5-aminolevulinic acid and homemade devices. Photodiagnosis Photodyn. Ther. 2012, 9, 60-68. [CrossRef]

52. Romano, R.A.; Silva, A.P.; Kurachi, C.; Guimara, F.E.G. Light-driven photosensitizer uptake increases Candida albicans photodynamic inactivation. J. Biophotonics 2017, 10, 1538-1546. [CrossRef] [PubMed]

53. Mello, B.L.; Alessi, A.M.; Riaño-Pachón, D.M.; DeAzevedo, E.R.; Guimarães, F.E.G.; Espirito Santo, M.C.; McQueen-Mason, S.; Bruce, N.C.; Polikarpov, I. Targeted metatranscriptomics of compost-derived consortia reveals a GH11 exerting an unusual exo-1,4- $\beta$-xylanase activity. Biotechnol. Biofuels. 2017, 10, 254. [CrossRef] [PubMed]

Publisher's Note: MDPI stays neutral with regard to jurisdictional claims in published maps and institutional affiliations.

(C) 2020 by the authors. Licensee MDPI, Basel, Switzerland. This article is an open access article distributed under the terms and conditions of the Creative Commons Attribution (CC BY) license (http://creativecommons.org/licenses/by/4.0/). 